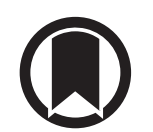

CrossMark

\title{
A guide for respiratory physiotherapy postgraduate education: presentation of the harmonised curriculum
}

\author{
Thierry Troosters ${ }^{1}$, Daniel Langer ${ }^{1}$, Chris Burtin $^{2}$, Michelle Chatwin $^{3}$, \\ Enrico M. Clini $\mathbb{1}^{4}$, Margareta Emtner ${ }^{5}$, Rik Gosselink ${ }^{1}$, Kathleen Grant ${ }^{6}$, \\ Deniz Inal-Ince ${ }^{7}$, Agnieszka Lewko ${ }^{8}$, Eleanor Main ${ }^{9}$, Beatrice Oberwaldner ${ }^{10}$, \\ Nathalie Tabin ${ }^{11}$ and Fabio Pitta ${ }^{12}$
}

\begin{abstract}
Affiliations: ${ }^{1}$ Dept of Rehabilitation Sciences, KU Leuven, Leuven, Belgium. ${ }^{2}$ REVAL Rehabilitation Research Center, BIOMED Biomedical Research Institute, Faculty of Rehabilitation, Hasselt University, Diepenbeek, Belgium. ${ }^{3}$ Academic and Clinical Dept of Sleep and Breathing and NIHR Respiratory Biomedical Research Unit, Royal Brompton and Harefield NHS Foundation Trust, London, UK. ${ }^{4}$ Dept Medical and Surgical Sciences, University of Modena Reggio Emilia and University Hospital of Modena Policlinico, Modena, Italy. ${ }^{5}$ Depts of Neuroscience and Medical Sciences, Uppsala University, Uppsala, Sweden. ${ }^{6}$ Dept of Cardio-respiratory Physiotherapy, Vaud University Hospital, Lausanne, Switzerland. ${ }^{7}$ Dept of Physiotherapy and Rehabilitation, Faculty of Health Sciences, Hacettepe University, Ankara, Turkey. ${ }^{8}$ Dept of Rehabilitation Sciences, Faculty of Health, Social Care and Education, Kingston University and St. George's University of London, London, UK. ${ }^{9}$ Physiotherapy Dept, Great Ormond Street Institute of Child Health, University College London, London, UK. ${ }^{10}$ Postgraduate School, Medical University, Graz, Austria. ${ }^{11}$ Education Dept, European Respiratory Society, Lausanne, Switzerland. ${ }^{12}$ Dept of Physiotherapy, Laboratory of Research in Respiratory Physiotherapy (LFIP) State University of Londrina (UEL), Londrina, Brazil.
\end{abstract}

Correspondence: Thierry Troosters, UZ Gasthuisberg, Respiratory Division, Research and Development Building 1 Box 706, Herestraat 49, 3000 Leuven, Belgium. E-mail: thierry.troostersakuleuven.be

@ERSpublications

The ERS respiratory physiotherapy curriculum sets a new standard for postgraduate respiratory physiotherapy education. It was developed to promote evidence-based practice and physical skills for the respiratory physiotherapist. http://bit.ly/2LwJ0mb

Cite this article as: Troosters T, Langer D, Burtin C, et al. A guide for respiratory physiotherapy postgraduate education: presentation of the harmonised curriculum. Eur Respir J 2019; 53: 1900320 [https://doi.org/10.1183/13993003.00320-2019].

Harmonising education is one of the most important challenges to ensure mobility of healthcare professionals across countries and regions of the world. While patients are affected by the same diseases, the healthcare systems in which they are cared for are very different and the healthcare providers within these systems are trained very differently. Health education in many countries is largely based on tradition. This is true for most medical specialities, as well as for physical therapy education [1], including respiratory physiotherapy. The responsibilities and the degree of professional and academic training vary widely across countries and regions [2]. While all educational programmes are probably fit for purpose within a given healthcare system, the variability in knowledge, skills and attitudes makes mobility and cross-certification difficult, if not impossible. In addition, the growing body of evidence for respiratory physiotherapy [3] makes it all the more important to foresee a framework for postgraduate training that prepares the workforce for the future [4]. For a global organisation, such as the European Respiratory Society (ERS), it also challenging to design postgraduate education that matches the level of knowledge and skills of all members. The ERS has a long tradition of providing such frameworks for harmonised 
education and training in respiratory medicine [5]. Figure 1 provides an overview of all available curricula and certified training programmes.

The design of a European (or global) curriculum for respiratory physiotherapy provides a platform for educational tracks to match specific educational programmes to the current consensus of what is expected from a trained respiratory physiotherapist. It also makes suggestions as to how the knowledge, skills and attitudes can be obtained, and at which level they should be examined. Importantly, this curriculum also provides third parties (chest physicians, general practitioners, nurses, thoracic surgeons, intensivists, funders and patients) with a comprehensive description of what they can expect from a trained respiratory physiotherapist.

Physiotherapy is becoming more and more specialised. In several countries respiratory physiotherapy is a recognised subspecialty of physiotherapy. In Belgium, for example, six particular competencies are recognised today [6] and this list is growing. These include a particular competency in manual therapy, paediatric conditions, and respiratory physiotherapy. In the USA, nine specialties are recognised by the American Physical Therapy Association (APTA). Therefore, it is no surprise that other branches of physical therapy have undertaken similar efforts to provide a standard set of expected knowledge, skills and attitudes. In the speciality of orthopaedic manipulative therapy such a curriculum (or standard) has existed since 1977 [7]. The APTA recognises a "cardiopulmonary physical therapist", and has a residency programme in accredited centres [8], as well as a formal exam for accreditation as a cardiorespiratory physical therapist.

The ERS respiratory physiotherapy curriculum sets a new standard for post-graduate respiratory physiotherapy education [9]. It was developed to promote evidence-based practice and physical skills for the respiratory physiotherapist, but also incorporates the expectations of other healthcare professionals who were involved in the development. The syllabus and curriculum are tailored to the needs of physical therapists who completed their physical therapy training (or training in rehabilitation sciences) according to the standards set out by the World Confederation of Physical Therapy (WCPT) [10]. This is important as it is expected that all respiratory physiotherapists should comply with the general professional attitudes required from a trained physiotherapist at entry level. These attitudes encompass accountability, humanity, compassion/caring, cultural competence, ethical behaviour, integrity, personal and professional development, professional duty, social responsibility and advocacy, and teamwork [10].

Admittedly, the curriculum developed by the task force sets the bar high, both in terms of knowledge needs as well as with regards to the skills and attitudes required from a professional. Conscious of the high standards, the curriculum is modular, with a separate adult and paediatric track, and additional modules

FIGURE 1 Overview of the portfolio of curricula and certified training programmes which have been developed by the ERS or are underway. See www.ersnet.org/professionaldevelopment/ers-curriculum-designa-summary-of-projects for more information and relevant publications. EBUS: endobronchial ultrasound.

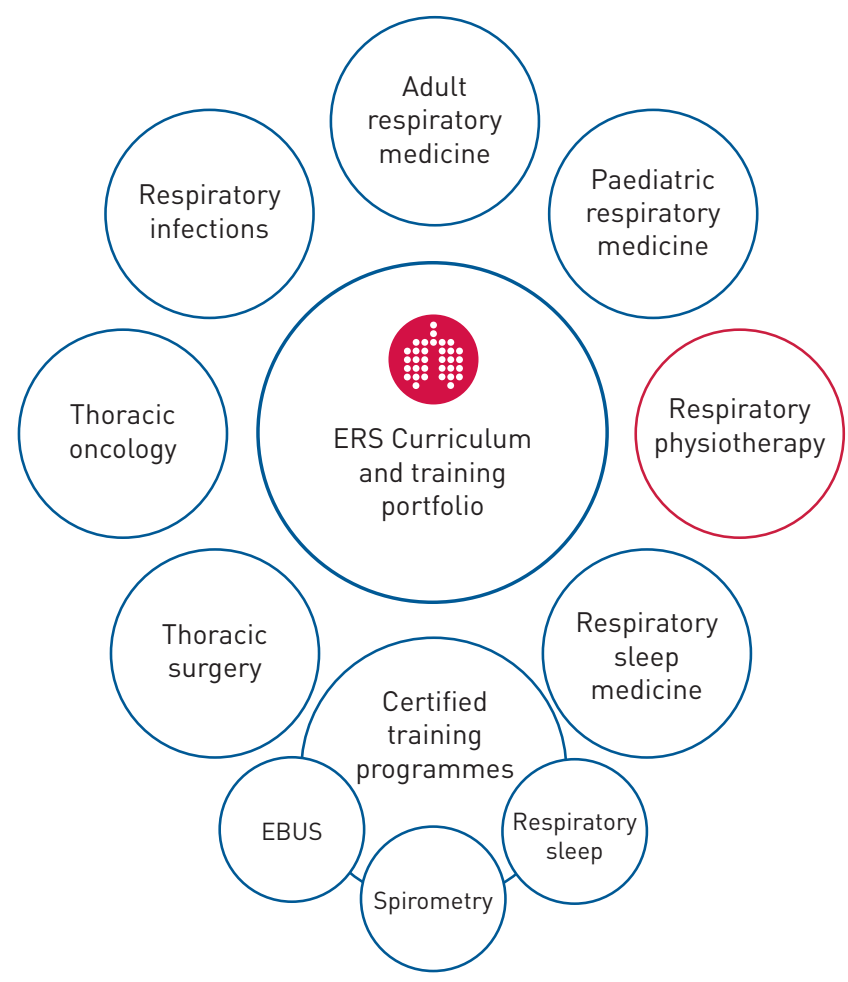


for intensive care. This choice was made in order to accommodate the clinical reality of subspecialised professionals who are often dealing with very specific patient populations and those that may only treat adult or paediatric patients.

Respiratory physiotherapists are professionals who collaborate within multidisciplinary teams and the success of their actions is often measured by the success of the whole team. The developed curriculum fits nicely with the "description of physical therapy" provided by the WCPT. This description highlights the competences of the physiotherapist in: 1) undertaking and evaluating the findings of examinations and assessments; 2) formulating a diagnosis, prognosis and treatment plan within their field of expertise; 3) providing consultation and determining when clients need to be referred to another professional; 4) implementing a physical therapy intervention; 5) determining the outcomes for such an intervention; and 6) making recommendations for self-management [10].

The present curriculum contains not only items that need to be "known" by respiratory physiotherapists, but also includes the skills and attitudes that can be expected from respiratory physiotherapists. In addition, suggested forms of teaching as well as methods for assessment are proposed. Though recognisably difficult, whenever possible suggestions are made for minimal clinical training or exposure. This may prove to be the "weak spot" of the present curriculum. While it is clear that clinical exposure is necessary to provide proper patient care, the exact quantity of that exposure is variable and hard to grasp. Nevertheless, whenever possible, based on educational experience and validated by the expert reviewers, a best guess was made for relevant clinical exposure. As it stands now, the proposed curriculum provides educators with a blueprint for teaching, skills training and practical training.

The curriculum is broad and spans the areas previously laid out in the syllabus [2]. The latter was developed with direct input from a large panel of worldwide experts. Similarly, both the adult and paediatric tracks of the curriculum have been subject to peer review to ensure acceptability and credibility. Upon publication, members of the ERS will be able to provide input to the curriculum as it is seen as a dynamic document that can, and should, be adapted over time.

In the document, all aspects of respiratory therapy are included. This does not mean that it is exclusively for respiratory physiotherapists. In different countries several healthcare professionals may have specific competencies. For example, this is the case for exercise training, noninvasive mechanical ventilation or mechanical ventilation. It is therefore important to align the local/regional requirements and local legal arrangements. In any case, physiotherapists have the competences to set-up fruitful interdisciplinary collaborations and this is also made clear throughout the document.

The next steps are to compare the content of the curriculum with existing educational programmes in different countries and to then subsequently align the educational opportunities of the ERS with the curriculum and establish accredited centres where practical skills training as well as clinical training can be performed. The leadership of ERS Group 9.2 (Physiotherapy) is committed to set out a pathway towards implementation and acceptance of the curriculum so that it can become an international standard for training in respiratory physiotherapy. Since accreditation of physiotherapists (as for other healthcare specialists) is organised at a country level, the ambition of ERS is not to provide a certificate for accreditation. Rather, the idea is to organise modules that individual members can use as part of their own portfolio to seek recognition as a respiratory physiotherapy specialist within their own accreditation environment, or in an environment they wish to transfer to as part of healthcare professionals' mobility.

The current syllabus and curriculum will provide a framework for international training in respiratory physiotherapy. It advises what knowledge, skills and attitudes need to be mastered by a respiratory physiotherapist. It also provides an indication for clinical training time, different forms of learning and examination. The syllabus and curriculum contain the elements around which an E-portfolio can be built, and it sets out a benchmark for endorsement of educational opportunities organised by others as well as the ERS. The expert group now invites the respiratory physiotherapy community to verify the proposed curriculum against their own. As this is a dynamic document, feedback is welcome. Furthermore, within the Group 9.2 (Physiotherapy) this project is now managed in order to exploit the curriculum to the benefit of all its members.

Acknowledgements: This task force was supported by the European Respiratory Society. The task force members want to thank all participants at the different stages of consultation throughout the process. We are also grateful to the ERS staff Sharon Mitchell and Alexandra Niculescu for their dedicated support in the development of the syllabus and curriculum.

Conflict of interest: T. Troosters is a member of European Respiratory Society core management group. D. Langer has nothing to disclose. C. Burtin has nothing to disclose. M. Chatwin reports personal fees from Breas, Resmed, and Philips (lecturing fees), outside the submitted work. E.M. Clini has nothing to disclose. M. Emtner has nothing to 
disclose. R. Gosselink has nothing to disclose. K. Grant has nothing to disclose. D. Inal-Ince has nothing to disclose. A. Lewko has nothing to disclose. E. Main has nothing to disclose. B. Oberwaldner has nothing to disclose. N. Tabin is an employee of the European Respiratory Society. F. Pitta has nothing to disclose.

\section{References}

1 Foo JS, Storr M, Maloney S. Registration factors that limit international mobility of people holding physiotherapy qualifications: a systematic review. Health Policy 2016; 120: 665-673.

2 Mitchell S, Pitta F, Troosters T. Standardised education and training for respiratory physiotherapists. Breathe 2013; 9: 171-174.

3 Denehy L, Granger CL, El-Ansary D, et al. Advances in cardiorespiratory physiotherapy and their clinical impact. Expert Rev Respir Med 2018; 12: 203-215.

4 Skinner EH, Williams CM, Haines TP. Embedding research culture and productivity in hospital physiotherapy departments: challenges and opportunities. Aust Health Rev 2015; 39: 312-314.

5 Loddenkemper R, Séverin T, Eiselé JL, et al. HERMES: Good reasons for harmonising education and training in respiratory medicine. Eur Respir J 2006; 28: 470-471.

6 Federal Ministery of Health. Royal decree for particular competences for physical therapists. Royal decree 2014 p. 57908. http://www.ejustice.just.fgov.be/cgi_loi/change_lg.pl?language=nl\&la=N\&cn=20140425G3\&table_name=wet

7 Lonneman ME, Olson KABJ. The history of IFOMPT: paving the way to global leadership in OMPT excellence. J Man Manip Ther 2017; 25: 223-226.

8 Furze JA, Tichenor CJ, Fisher BE, et al. Physical therapy residency and fellowship education: reflections on the past, present, and future. Phys Ther 2016; 96: 949-960.

9 Troosters $\mathrm{T}$, Tabin $\mathrm{N}$, Langer $\mathrm{D}$, et al. Introduction of the harmonised respiratory physiotherapy curriculum. Breathe 2019; 15: 110-115.

10 World Confederation of Physical Therapy (WCPT). Policy statement: description of physical therapy. 2015; pp. 1-9. https://www.wcpt.org/sites/wcpt.org/files/files/resources/policies/2017/PS_Description_of_physical_therapy_ FINAL.pdf 